\title{
Revisiting the Role of Vacancies in Manganese Related Perovskites
}

\author{
Luisa Ruiz-González ${ }^{1}$, Raquel Cortés-Gil ${ }^{1,2}$, José M. Alonso ${ }^{2,3}$, José M. González-Calbet ${ }^{1}$ and \\ María Vallet-Regí*,
}

\author{
${ }^{1}$ Departamento de Química Inorgánica, Facultad de Químicas, Universidad Complutense, 28040-Madrid, Spain \\ ${ }^{2}$ Instituto de Magnetismo Aplicado, UCM-CSIC-RENFE, Las Rozas, P.O. Box 155, 28230-Madrid, Spain \\ ${ }^{3}$ Instituto de Ciencia de Materiales, CSIC, Sor Juana Inés de la Cruz s/n, 28049-Madrid, Spain \\ ${ }^{4}$ Departamento de Química Inorgánica y Bioinorgánica, Facultad de Farmacia, Universidad Complutense, 28040- \\ Madrid, Spain
}

\begin{abstract}
Oxygen engineering is an important tool for on-demand tailoring of manganese related perovskites into optimized performances. Anionic vacancies can be induced in both doped and undoped manganites by means of topotactic reduction processes under oxygen controlled atmosphere. This has given rise to the stabilization of new phases as a consequence of ordering of oxygen vacancies in which $\mathrm{Mn}^{2+}$ appears due to the reducing process. Different reduction pathways are proposed for $\mathrm{LaMnO}_{3}$ and doped systems. FM interactions remain at the octahedral layers when vacancies are longrange ordered. The peculiar magnetic behaviour of new layered perovskite superstructures is discussed.
\end{abstract}

Keywords: Manganese related perovskites, colossal magnetoresistance, oxygen non-stoichiometry, cationic vacancies, anionic vacancies.

\section{INTRODUCTION}

Ever since colossal magnetoresistence (CMR) was discovered in $\mathrm{Ln}_{1-\mathrm{x}} \mathrm{AT}_{\mathrm{x}} \mathrm{MnO}_{3}(\mathrm{Ln}=$ lanthanide and $\mathrm{AT}=$ alkalineearth), establishing the relationship between structures and properties in this system occupies a prominent place in the landscape of solid-state science because of their intriguing potential applications [1,2]. Systems exhibiting different compositions have been studied where $\mathrm{La}_{1-\mathrm{x}} \mathrm{Ca}_{\mathrm{x}} \mathrm{MnO}_{3}$ is probably the best known system. From the structural point of view, a solid solution with an orthorhombic perovskite structure (S.G. Pnma), $a \cong a_{c} \sqrt{ } 2 b \cong 2 a_{c}, c \cong a_{c} \sqrt{ } 2$ (where $a_{c}$ stands for the basic parameter of the cubic subcell) exists over the whole compositional range. In spite of this apparent simplicity, the solid solution exhibits a complex magnetic and electric behaviour depending on the $\mathrm{x}$ value, i.e., the calcium content $[3,4]$. This fact is related to the manganese oxidation state, $\mathrm{Mn}^{3+}$ for $\mathrm{LaMnO}_{3}(\mathrm{x}=0)$ while $\mathrm{Mn}^{4+}$ appears as a consequence of the alkaline-earth substitution. The occurrence of different $\mathrm{Mn}^{3+} / \mathrm{Mn}^{4+}$ ratios, over the whole system, is responsible for the different magnetic behaviours observed. In this sense, Schiffer phase diagram [3] establishes ferromagnetic $(\mathrm{FM})$ and metallic $(\mathrm{M})$ character in the $0.2 \leq \mathrm{x}<0.5$ range as well as the higher CMR values at higher temperatures. For $\mathrm{x}=0.5$, FM and charge ordering $(\mathrm{CO})$ coexist while an antiferromagnetic (AFM) and insulator (I) character is observed for higher $\mathrm{x}$ values. The $\mathrm{CO}$ state represents the limit between the FM/M and AFM/I behaviours being controlled by the $\mathrm{Mn}^{3+} / \mathrm{Mn}^{4+}$ ratio. Thus, when such a ratio is in between $0.20<\mathrm{Mn}^{3+} / \mathrm{Mn}^{4+}<1$ the system is $\mathrm{FM} / \mathrm{M}$, whereas for $\mathrm{Mn}^{3+} / \mathrm{Mn}^{4+} \geq 1$ it turns AFM/I.

*Address correspondence to these authors at the Departamento de Química Inorgánica y Bioinorgánica, Facultad de Farmacia, Universidad Complutense, 28040-Madrid, Spain; E-mail: vallet@ farm.ucm.es
On the basis of the above mentioned diagram, it was though that Mn oxidation state was controlled by calcium or in general by the alkaline earth. This is, in fact, a possibility but there are other chemical strategies that must be considered. In so doing, the Mn oxidation state can be modified by introducing vacancies in either of both, cation or anion, sublattices. Actually, cation vacancies are created in $\mathrm{LaMnO}_{3}$, when treated under oxidizing atmosphere, in accordance to the $\mathrm{La}_{1-\mathrm{t}} \mathrm{Mn}_{1-\mathrm{t}} \mathrm{O}_{3}$ formula $[5,6]$. This is possible because the perovskite structure does not admit interstitial oxygen and instead of that the system develops on the $\mathrm{Mn}$ and La vacancy formation. As a consequence, $\mathrm{Mn}^{4+}$ appears and then $\mathrm{Mn}^{4+}-\mathrm{O}-\mathrm{Mn}^{3+}$ interact through a shared oxygen in the perovskite structure giving rise to double exchange interactions [7]. The $\mathrm{Mn}^{3+} / \mathrm{Mn}^{4+}$ ratio can be, subsequently, modified by changing the oxidizing conditions. The important conclusion is that $\mathrm{La}_{1-\mathrm{t}} \mathrm{Mn}_{1-\mathrm{t}} \mathrm{O}_{3}$ exhibits $\mathrm{FM}$ and $\mathrm{M}$ behaviour [8-11] as observed in Ca doped manganites. It has been proposed that the cationic vacancies create $\mathrm{Mn}^{4+}$ acting as effective attractors of these holes and promoting the FM interactions with the surrounding $\mathrm{Mn}^{3+}$. In a similar fashion, these ideas can be extended to the calcium system. In fact, we have recently shown that the introduction of cationic vacancies $[12,13]$, at the $\mathrm{A}$ and $\mathrm{B}$ perovskite sublattice, in $\mathrm{La}_{1}$. ${ }_{x} \mathrm{Ca}_{\mathrm{x}} \mathrm{MnO}_{3}$ induces a drastic increase of the magnetization in the whole range of temperatures leading to a FM. It can be explained taking into account the increase of $\mathrm{Mn}^{4+}$ concentration and formation of $\mathrm{Mn}^{4+}-\mathrm{O}-\mathrm{Mn}^{3+}$ clusters which are FM and locally conductors. For low $\mathrm{Ca}^{2+}$ concentration $(<20 \%)$, the clusters are isolated and the material is an insulator. The oxidation process promotes an increase of the $\mathrm{Mn}^{4+}$ concentration which is located around $\mathrm{Ca}^{2+}$ positions. The clusters are still isolated and the material preserves the insulator character but becomes FM. The metallic behaviour is attained when the clusters contact and interact. The system percolates and turns metallic. Moreover, the introduction of 
vacancies only at the A position [14-15] can lead to materials with a $50 \%$ of $\mathrm{Mn}^{4+}$ without charge ordering. Actually, $\mathrm{La}_{0.5} \mathrm{Ca}_{0.5} \mathrm{MnO}_{3}$ shows a paramagnetic-ferromagnetic transition at $T_{c}=223 \mathrm{~K}$ whereas at $\mathrm{T}=190 \mathrm{~K}$ the magnetization decreases and becomes AFM with charge ordering [16-18]. This situation changes when cationic vacancies are introduced at the A position leading to a drastic increase of the magnetization value in the whole temperature range. These materials do not only exhibit FM and M character without charge ordering but they also show an increase of the magnetoresistence values in the whole temperature range. On the other hand, for a fixed calcium content, such as $\mathrm{x}=0.5$ for instance, the $\mathrm{Mn}^{3+} / \mathrm{Mn}^{4+}$ ratio can be modified by creation of anionic vacancies [15]. Actually, for a small concentration of anionic vacancies, the FM fraction in $\mathrm{La}_{0.5} \mathrm{Ca}_{0.5} \mathrm{MnO}_{3-\delta}$ [19] increases as the $\mathrm{CO}$ fraction decreases. This effect is due to the progressive elimination of the $\mathrm{CO}$ state as a consequence of the $\mathrm{Mn}^{3+} / \mathrm{Mn}^{4+}$ ratio increasing. For high vacancy concentration the double exchange interactions are suppressed and the FM ordering disappears.

These systems constitute interesting examples of how the Mn oxidation state influences on their properties. Mn can also show a more reduced oxidation state, i.e., $\mathrm{Mn}^{2+}$ which could be, in principle, stabilized by $\mathrm{LaMnO}_{3}$ (or other related systems) reduction. The introduction of $\mathrm{Mn}^{2+}$ would lead to $\mathrm{Mn}^{2+}-\mathrm{O}-\mathrm{Mn}^{3+}$ interactions which together with the anion vacancies creation must necessarily affect both structural and magnetic properties. Nevertheless, not many studies have been focused to compositional variations at the anionic sublattice of $\mathrm{La}_{1-\mathrm{x}} \mathrm{Ca}_{\mathrm{x}} \mathrm{MnO}_{3}$ manganites except for $\mathrm{x}=1$, which comprises the $\mathrm{CaMnO}_{3}$ composition and then $\mathrm{Mn}^{4+}$. The reduction process of $\mathrm{CaMnO}_{3-\delta}$ leads to different phases, showing mixtures of $\mathrm{Mn}^{4+}$ and $\mathrm{Mn}^{3+}$, built up from squaredbased pyramids and octahedral intergrowths, in the $0 \leq \delta<0.5$ range [20]. For $\delta=0.5$ a phase involving only square-based pyramids sharing corners (Fig. 1a) and $\mathrm{Mn}^{3+}$ is attained. The $\mathrm{CaMnO}_{2.5}$ structure can be derived from the perovskite if one of each two oxygen positions in every (010) plane is eliminated along the $[101]_{\mathrm{c}}$ direction, as schematically represented in Fig. (2a-b). The reduction process of $\mathrm{La}_{1-\mathrm{x}} \mathrm{Ca}_{\mathrm{x}} \mathrm{MnO}_{3-\delta}$ $(\delta<1)$ has been by far less studied. In fact, the topotactic reduction process $\mathrm{CaMnO}_{2.5} \rightarrow \mathrm{CaMnO}_{2}$ [21], where $\mathrm{CaMnO}_{2}$ is a rock-salt type oxide, does not lead to intermediate phases with $\mathrm{Mn}^{3+}$ and $\mathrm{Mn}^{2+}$.


Fig. (1). Structural model along [001] of (a) $\mathrm{Ca}_{2} \mathrm{Mn}_{2} \mathrm{O}_{5}$ and (b) Brownmillerite.

Tunability of oxygen non-stoichiometry is a common strategy which applied to the control of Mn oxidation states opens new possibilities in the $\mathrm{La}_{1-\mathrm{x}} \mathrm{Ca}_{\mathrm{x}} \mathrm{MnO}_{3-\delta}$ system. In this way, Kamata et al. [22] suggested the stabilization of $\mathrm{LaMnO}_{3-\delta}$ in the $0.00 \leq \delta \leq 0.05$ range with a random distribution of the oxygen vacancies, while for higher concentration it decomposed to $\mathrm{La}_{2} \mathrm{O}_{3}$ and $\mathrm{MnO}$. In fact, González-Calbet et al. [23] stabilized an oxygen deficient manganese related perovskite, $\mathrm{La}_{0.5} \mathrm{Ca}_{0.5} \mathrm{MnO}_{2.5}$, with the brownmillerite type. The brownmillerite structure is built up from the ordered intergrowth, along $\mathrm{b}$, of octahedral and tetrahedral layers (Fig. 1b). The different orientation of the consecutive tetrahedral layers gives rise to a four-fold superlattice, of the cubic perovskite, along $\mathrm{b}$. It can be derived from the perovskite structure by eliminating oxygen in alternating rows along $[101]_{\mathrm{c}}$ direction in alternates planes along $\mathrm{b}$, following the scheme depicted in Fig. (2b-c). Hansteen et al. [24] have reported $\mathrm{LaMnO}_{3-\delta}(0.08 \leq \delta<0.25)$ but mixtures of phases were obtained through a zircothermal reduction processes. More recently, $\mathrm{LaMnO}_{2.75}(\delta=0.25)$ has been stabilized by topotactic reduction of $\mathrm{LaMnO}_{3}$ in a thermobalance [25] hence showing that further oxygen reduction can be obtained if $\mathrm{La}$ is partially substituted by $\mathrm{Ca}$ [23] or $\mathrm{Sr}$ [26].

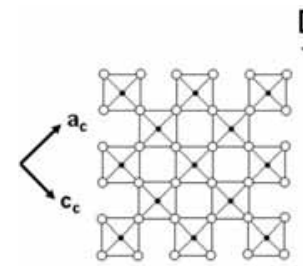

(a) $[101]_{c}$

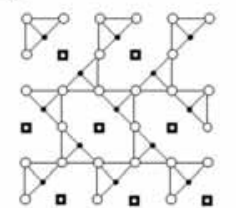

(b)

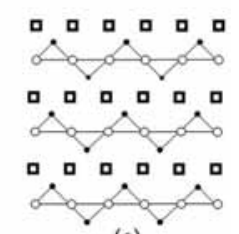

(c)

$$
\begin{aligned}
& \text { O } \\
& \text { - Mn } \\
& \text { - vacancy }
\end{aligned}
$$

Fig. (2). Schematic representation of the ordered vacancy arrangement respect (a) the perovskite cubic sublattice for (b) $\mathrm{Ca}_{2} \mathrm{Mn}_{2} \mathrm{O}_{5}$ and (c) brownmillerite structural types.

The aim of this work is to analyse in depth the reduction process of $\mathrm{La}_{1-\mathrm{x}} \mathrm{AT}_{\mathrm{x}} \mathrm{MnO}_{3}(\mathrm{AT}=\mathrm{Ca}, \mathrm{Sr}$ ) focussing, mainly, on chemical and structural concerns related to the reaction. In this sense, we will concentrate on $\mathrm{LaMnO}_{3-\delta}(\mathrm{x}=0)$ and $\mathrm{La}_{0.5} \mathrm{Sr}_{0.5} \mathrm{MnO}_{3-\delta}(\mathrm{x}=0.5)$ systems, in which we have recently reported the stabilization of $\mathrm{LaMnO}_{2.75}$ [25] and $\mathrm{La}_{0.5} \mathrm{Sr}_{0.5} \mathrm{MnO}_{2.5}$ [26], whereas the reaction pathway as well as the stabilization of other reduced phases has not been described in detail. Moreover, the $\mathrm{Ln}_{0.5} \mathrm{AT}_{0.5} \mathrm{MnO}_{3-\delta}$ system admits compositional changes at the Ln and AT sublattice while the oxygen stoichiometry is kept constant and equal to 2.5. A representative example is, as already mentioned, the $\mathrm{La}_{0.5} \mathrm{Ca}_{0.5} \mathrm{MnO}_{2.5}$ compound [23] opening new expectations to the stabilization of new brownmillerite-related materials if $\mathrm{La}$ is substituted by another lanthanide. Moreover, as studied in the more oxidized materials $\left(\mathrm{Ln}_{0.5} \mathrm{AT}_{0.5} \mathrm{MnO}_{3}\right)$, changes on the $\mathrm{Ln} / \mathrm{AT}$ ratio must lead to further changes in the Mn oxidation state of $\mathrm{Ln}_{1-\mathrm{x}} \mathrm{AT}_{\mathrm{x}} \mathrm{MnO}_{2.5}$ and then to properties modification. In order to proceed with the above syntheses, it is essential to control the exact stoichiometry of the starting material because it will influence on the subsequent stabilization of the reduced materials. No accurate interpretation of the material features of manganese related perovskites can be made without precise knowledge of the oxygen content of the samples. 


\section{MATERIALS AND METHODS}

\section{$\mathrm{LaMnO}_{3-\delta}$}

$\mathrm{LaMnO}_{3}$ starting material was synthesized by using the ceramic method at $1400{ }^{\circ} \mathrm{C}$ for 120 hours with several intermediate grindings and final quenching in liquid nitrogen.

Cationic composition, as determined by X-ray energy dispersive spectroscopy (XEDS), leads to La:Mn $=1: 1$ ratio. Oxygen content was established by thermogravimetric analysis using a Cahn D-200 electrobalance equipped with a furnace and a two-channel register, allowing the simultaneous recording of the weight loss and the reaction temperature. The sample, around $100 \mathrm{mg}$, was heated in a $\mathrm{H}_{2}(200$ mbar) and $\mathrm{He}(300 \mathrm{mbar})$ atmosphere up to $1000{ }^{\circ} \mathrm{C}$ at 6 ${ }^{\circ} \mathrm{C} / \mathrm{min}$ rate. As can be observed, around $450{ }^{\circ} \mathrm{C}$ the reduction process starts ending for $3-\delta=2.5$ (Fig. 3a). The analysis of the reduction products $\left(\mathrm{La}_{2} \mathrm{O}_{3}\right.$ and $\left.\mathrm{MnO}\right)$ and the weight loss together with the cationic stoichiometry data indicates the stabilization of a sample, in accordance with volumetric analysis, with the general formula $\mathrm{LaMnO}_{3}$.
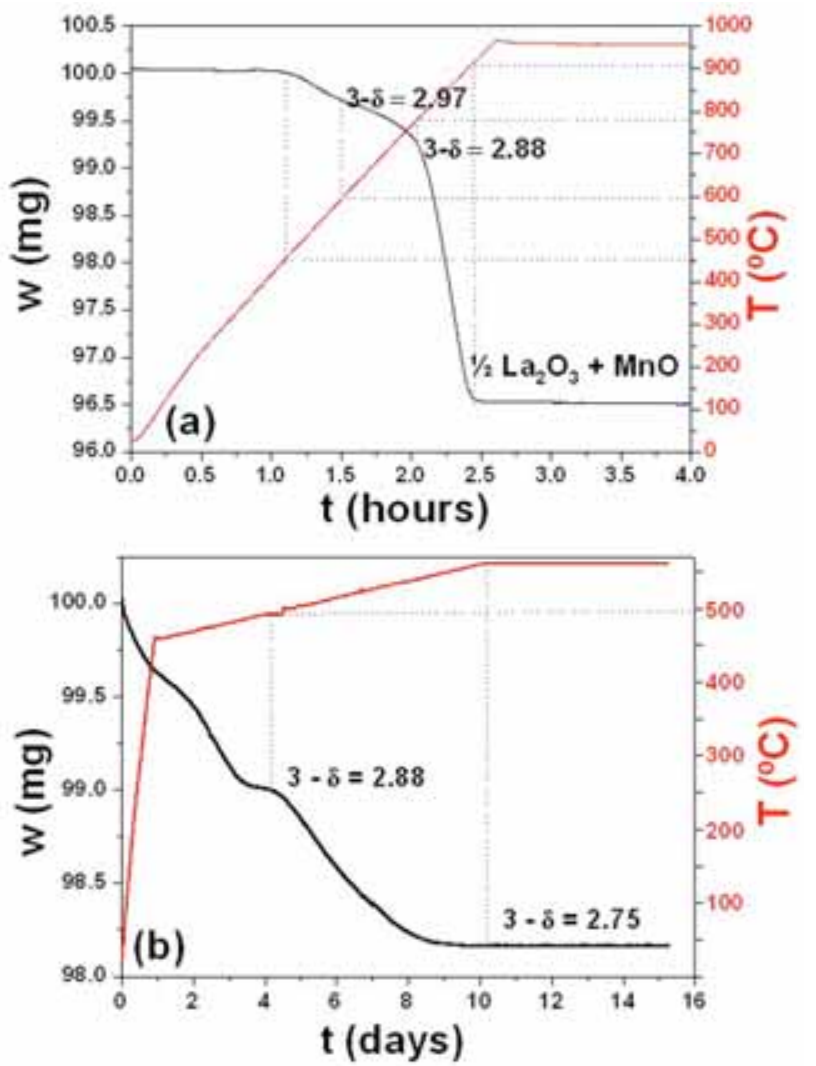

Fig. (3). Thermogravimetric curves corresponding to (a) total reduction process of $\mathrm{LaMnO}_{3}$ and (b) partial reduction process until $\mathrm{LaMnO}_{2.75}$.

Once the cationic and anionic composition was checked, the thermogravimetric curve was studied. In the above conditions two plateaux, corresponding to oxygen contents of 2.97 and 2.88 per unit formula, are observed. In order to investigate other possible oxygen stoichiometries, slower kinetic conditions were applied. In this sense, the reducing atmosphere was identical but the heating rate of $6{ }^{\circ} \mathrm{C} / \mathrm{min}$ was maintained up to $450{ }^{\circ} \mathrm{C}$ and once reached, the rate was decreased at $0.02{ }^{\circ} \mathrm{C} / \mathrm{min}$ up to $560{ }^{\circ} \mathrm{C}$, leading to the thermogravimetric reduction shown in (Fig. 3b). In this curve, a new plateau at $560{ }^{\circ} \mathrm{C}$, corresponding to oxygen content 2.75 per unit formula, is evident.

On the basis of these results, the $\mathrm{O}_{2.88}$ sample was prepared in similar conditions. In this case, the only difference respect to $\mathrm{O}_{2.75}$ was the final temperature reached: $500{ }^{\circ} \mathrm{C}$. For $\mathrm{O}_{2.97}$, the sample was heated at $6{ }^{\circ} \mathrm{C} /$ min until $450{ }^{\circ} \mathrm{C}$. In all the cases, once the desired oxygen content was obtained, the reducing atmosphere was replaced by inert conditions (500 mbar He atmosphere), and the samples were annealed during some days at the corresponding target temperature, respectively. Finally, the sample is quenched. Attempts to stabilize other oxygen contents failed.

\section{$\mathbf{L a}_{0.5} \mathbf{S r}_{0.5} \mathbf{M n O}_{3-\delta}$}

The starting material was the $\mathrm{La}_{0.5} \mathrm{Sr}_{0.5} \mathrm{MnO}_{3}$ perovskite, synthesized by ceramic method from stoichiometric amounts of $\mathrm{La}_{2} \mathrm{O}_{3}, \mathrm{SrCO}_{3}$ and $\mathrm{MnO}_{2}$ at $1400{ }^{\circ} \mathrm{C}$ for 100 hours, with several intermediate grindings followed by final quenching in air. The experimental composition, as determined by XEDS and thermogravimetric analysis, is in agreement with the nominal one. Samples with $\mathrm{La}_{0.5} \mathrm{Sr}_{0.5} \mathrm{MnO}_{2.67}$ and $\mathrm{La}_{0.5} \mathrm{Sr}_{0.5} \mathrm{MnO}_{2.5}$, compositions were stabilized by heating in $\mathrm{H}_{2}$ (200 mbar) and $\mathrm{He}$ (300 mbar) atmosphere (Fig. 4). In the $\mathrm{La}_{0.5} \mathrm{Sr}_{0.5} \mathrm{MnO}_{2.67}$ case, the heating rate of $6{ }^{\circ} \mathrm{C} / \mathrm{min}$ was maintained up to $390{ }^{\circ} \mathrm{C}$ (temperature at which reduction starts) and once reached, the rate was decreased at 0.02 ${ }^{\circ} \mathrm{C} /$ min up to $460{ }^{\circ} \mathrm{C}$. For $\mathrm{La}_{0.5} \mathrm{Sr}_{0.5} \mathrm{MnO}_{2.5}$ the heating rate of $6{ }^{\circ} \mathrm{C} / \mathrm{min}$ was maintained up to $630{ }^{\circ} \mathrm{C}$. Once a desired weight loss was reached, the samples were treated at the same conditions described for $\mathrm{LaMnO}_{3-\delta}$ system.



Fig. (4). Thermogravimetric curve corresponding to total reduction process of $\mathrm{La}_{0.5} \mathrm{Sr}_{0.5} \mathrm{MnO}_{3}$. The inset shows the partial reduction process until $\mathrm{O}_{2.5}$.

Samples with different compositions at the A sublattice such as $\quad \mathrm{La}_{0.5} \mathrm{Ca}_{0.5} \mathrm{MnO}_{2.5}, \quad \mathrm{Nd}_{0.5} \mathrm{Sr}_{0.5} \mathrm{MnO}_{2.5}, \quad \mathrm{La}_{0.67} \mathrm{Ca}_{0.33}$ $\mathrm{MnO}_{2.5}$ and $\mathrm{La}_{0.33} \mathrm{Ca}_{0.67} \mathrm{MnO}_{2.5}$ were synthesized in a similar way to $\mathrm{La}_{0.5} \mathrm{Sr}_{0.5} \mathrm{MnO}_{2.5}$.

$\mathrm{X}$-ray diffraction (XRD) patterns were obtained in a Philips $\mathrm{X}^{\prime}$ Pert diffractometer equipped with a $\mathrm{Cu}_{\mathrm{K} \alpha}$ radiation source. Microstructural characterization was carried out on both JEOL 2000 FX and JEM-3000F electron microscopes equipped with microanalysis systems (Oxford Instruments). The magnetic properties were measured using a Quantum Design SQUID magnetometer in the temperature range from 5 to $300 \mathrm{~K}$ at applied fields of up to $5 \mathrm{~T}$. 


\section{RESULTS AND DISCUSSION}

\section{$\mathrm{LaMnO}_{3-\delta}$}

Once the optimal synthetic conditions were established three -apparently- single phases, corresponding to $\mathrm{LaMnO}_{2.97}, \mathrm{LaMnO}_{2.88}$ and $\mathrm{LaMnO}_{2.75}$, were obtained (Fig. 3). The XRD pattern of $\mathrm{LaMnO}_{2.97}$ and $\mathrm{LaMnO}_{2.88}$ can be indexed, as the $\mathrm{LaMnO}_{3}$ starting material, on the basis of an orthorhombic perovskite cell (Table 1), being remarkable the smaller distortion of the lower oxygen content sample.

Table 1. Lattice Parameters Corresponding to $\mathrm{LaMnO}_{3-\delta}$

\begin{tabular}{|c|c|c|c|}
\hline $\mathbf{L a M n O}_{3-\delta}$ & $\mathbf{a}(\mathbf{n m})$ & $\mathbf{b}(\mathbf{n m})$ & $\mathbf{c}(\mathbf{n m})$ \\
\hline \hline $\mathrm{LaMnO}_{3.0}$ & $0.554(2)$ & $0.771(2)$ & $0.571(2)$ \\
\hline $\mathrm{LaMnO}_{2.97}$ & $0.554(3)$ & $0.783(3)$ & $0.567(3)$ \\
\hline $\mathrm{LaMnO}_{2.88}$ & $0.555(3)$ & $0.796(3)$ & $0.556(3)$ \\
\hline $\mathrm{LaMnO}_{2.75}$ & $0.562(1)$ & $3.200(1)$ & $0.559(1)$ \\
\hline
\end{tabular}

A different situation was attained for $\mathrm{LaMnO}_{2.75}$ whose XRD pattern clearly shows superlattice reflections. In fact, it can be indexed on the basis of an eightfold perovskite structure along $\mathrm{b}$, isostructural to $\mathrm{Ca}_{4} \mathrm{Fe}_{2} \mathrm{Ti}_{2} \mathrm{O}_{11}[27,28]$, characteristic of the $n=4$ member of the $\mathrm{A}_{n} \mathrm{~B}_{\mathrm{n}} \mathrm{O}_{3 \mathrm{n}-1}$ homologous series [29] where (n-1) octahedral layers intergrow with a tetrahedral one. This homologous series responds to a systematic pathway through which perovskite compounds can accommodate oxygen vacancies as a consequence of their ordered arrangement, in accordance to the scheme depicted in Fig. (2c) which leads to tetrahedra formation. In this sense, the $n=2$ term (Fig. 5a) would be described from the alternation of one octahedral layer (n-1) and a tetrahedral one. Notice that this description corresponds to the brownmillerite structure, in agreement with the generic composition $\mathrm{A}_{2} \mathrm{~B}_{2} \mathrm{O}_{5}\left(\mathrm{ABO}_{2.5}\right)$. For $\mathrm{n}=3$ (Fig. 5b) two octahedral layers intergrow with a tetrahedral one, as described in $\mathrm{Ca}_{2} \mathrm{LaFe}_{3} \mathrm{O}_{8}$ [30]. The $\mathrm{n}=4$ term is (Fig. 5c) derived from the $\mathrm{n}=3$ by adding another octahedral layer, i.e., three octahedral layers intergrow with a tetrahedral one. It should be noticed

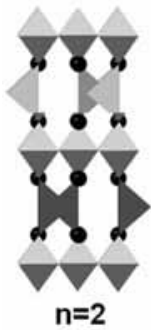

(a)

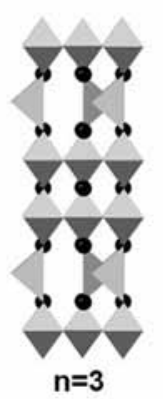

(b)

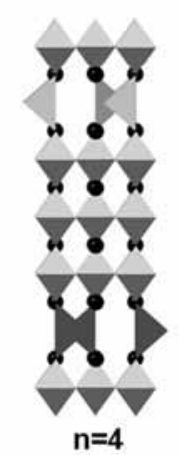

(c)

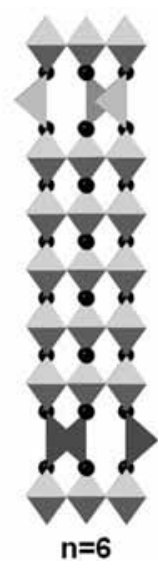

(d)
Fig. (5). $\mathrm{A}_{n} \mathrm{BnO}_{3 \mathrm{n}-1}$ homologous series polyhedra model. Notice that for simplicity reasons only half unit cells are represented for $\mathrm{n}=4$ and $\mathrm{n}=6$ terms. that the relative tetrahedra orientation, in consecutive layers, doubles the expected periodicity in $n=2$ and $n=4$ terms leading to four and eight fold superlattices, respectively, along $b$ direction.

These data suggest that the oxygen content decreasing for $\mathrm{LaMnO}_{2.97}$ and $\mathrm{LaMnO}_{2.88}$ does not affect to the average structure of $\mathrm{LaMnO}_{3}$, probably due to a random distribution of the oxygen vacancies. Further reduction results on the stabilization of an eightfold superlattice, in accordance to the model depicted in Fig. (6c) in which the tetrahedral layers are related to the oxygen vacancies formation and subsequently ordered arrangement in planes along b axis. Komornicki et al. [31], proposed a model in order to explain the behaviour of the anionic vacancies. They hypothesized that for low anionic vacancy concentration there is a tendency for random distribution. For $\delta$ values close to 0.15 , anionic vacancies start ordering along rows of different length, which are randomly distributed, developing into rows of infinite length for $\delta$ close to 0.20 . When $\delta$ approach the value 0.25 the ordering is extended to the second dimension giving rise to layers of defects. At the beginning, these planes are randomly arranged leading to local disordered intergrowths but they become ordered by increasing either the annealing times or the oxygen deficiency. In this sense, the absence of superstructure in $\mathrm{LaMnO}_{2.97}$ and $\mathrm{LaMnO}_{2.88}$ can be understood, specially, for $\mathrm{LaMnO}_{2.97}$ because it would involve, following the model of the homologous series $\mathrm{A}_{\mathrm{n}} \mathrm{B}_{\mathrm{n}} \mathrm{O}_{3 \mathrm{n}-1}$, the intergrowth of one tetrahedral layer with 33 octahedral layers. It is well known that this structural type would require "geological times", to get an ordered state as long as the required for the hypothetical $n=34$ term of the above series. The $\mathrm{LaMnO}_{2.88}$ composition is in between the one characteristic to the $\mathrm{n}=8\left(\mathrm{LaMnO}_{2.875}\right)$, which would involve intergrowth of one tetrahedral layer with 7 octahedral ones, and the $n=9$ $\left(\mathrm{LaMnO}_{2.89}\right)$, involving one tetrahedral and 8 octahedral layers, members of the series, being a more plausible situation compared to the above one. Between these two extreme situations, i.e., the one comprising ordered superlattices, due to vacancy ordering, and the other of randomly arranged
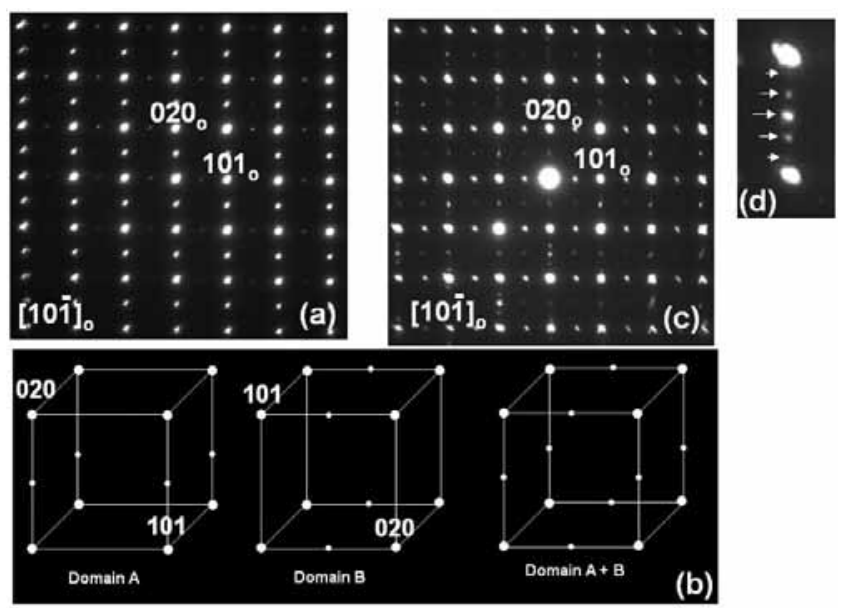

Fig. (6). (a) orthorhombic perovskite crystal in $\mathrm{LaMnO}_{2.88}$, (b) schematic representation of the reciprocal lattices of the two perpendicular domains (A and B) and the superposition of both $(A+B)$ present on figure a (c) SAED pattern characteristic of average sixfold superlattice crystal in $\mathrm{LaMnO}_{2.88}$ (d) enhanced detail showing clearly the above superlattice. 
vacancies, small clusters or short range phenomena are also possible, but not detectable by means of XRD. Actually, more precise structural information can be obtained by means of SAED and HREM which are powerful tools to visualize short range order phenomena.

SAED study for $\mathrm{LaMnO}_{2.97}$ confirms the orthorhombic perovskite cell in which vacancies must be randomly accommodated since no additional ordering has been detected. However, a more complex situation has been observed for $\mathrm{LaMnO}_{2.88}$ since two types of crystals are present. The first one is in agreement to the orthorhombic perovskite cell, as reflected in the characteristic pattern along [101] zone axis (Fig. 6a).

This pattern could be, apparently, indexed on the basis of a double cubic cell along two perpendicular directions whereas a more plausible situation is the presence of twinning, as schematically represented in Fig. (6b). In fact, this is well known [32] and very common phenomena appearing in different orthorhombic perovskites. The second type reflects the presence of order-disorder phenomena as shown in the representative SAED pattern (Fig. 6c) in which additional diffuse reflections appear along $b^{*}$. Notice that, in spite of their diffuse nature, five spots can be distinguished among the two more intense, characteristic of the basic lattice, suggesting a six-fold superlattice along $b$, better observed in the enhanced detail (Fig. 6d). This superstructure could be related to the hypothetical intergrowth of one tetrahedral and five octahedral layers, along $b$, characteristic of the $n=6$ term of the homologous $\mathrm{A}_{n} \mathrm{~B}_{\mathrm{n}} \mathrm{O}_{3 \mathrm{n}-1}$ series (Fig. 6d) involving the $\mathrm{LaMnO}_{2.83}$ composition.

These results indicate that $\mathrm{LaMnO}_{2.88}$ does not only consist on a single orthorhombic perovskite cell with random oxygen vacancies, as suggested by XRD, but, additionally, exhibits short range order-disorder phenomena. At this point, it is worth remembering that the $n=4$ term is the highest which has been stabilized, not only in the La-Mn-O system but also in others like Ca-Fe-Ti-O [24]. Moreover, even in these favourable cases, the $n=4$ term stabilization takes long annealing time, 15 and 45 days for $\mathrm{LaMnO}_{2.75}$ [25] and $\mathrm{Ca}_{4} \mathrm{Fe}_{2} \mathrm{Ti}_{2} \mathrm{O}_{11}$ [27], respectively, in agreement to Komornicki [31]. As the vacancy concentration becomes lower, the probability to find ordered regions decreases and attempts to stabilize $\mathrm{n}=6\left(\mathrm{LaMnO}_{2.83}\right)$ and $\mathrm{n}=8\left(\mathrm{LaMnO}_{2.875}\right)$ failed, leading to average perovskite structure. Nevertheless, this situation does not exclude local ordering phenomena, as happens for $\mathrm{LaMnO}_{2.88}$. Notice that, although it is just a qualitative approximation, the average $\mathrm{O}_{3}$ and $\mathrm{O}_{2.83}$ oxygen stoichiometry fits quite well, $\mathrm{O}_{2.9}$ to the sample one $\mathrm{O}_{2.88}$. This would be, indeed, an ideal situation because perovskite regions are majority and probably contain oxygen vacancies randomly distributed. In any case, it is clear that the vacancy ordering processes have been, at least locally, initiated for this oxygen defective composition. Further annealing treatment did not lead to long range ordering probably because the oxygen vacancy concentration is not high enough. When this concentration increases, the $\mathrm{LaMnO}_{2.75}$ phase is stabilized and the SAED and HREM study confirms the eight-fold superlattice [25] along b. It is worth mentioning that order-disorder phenomena has not been detected but different orientated domains are present as reflected in Fig. (7a) in which domains along [100] and [001] coherently intergrow. Notice that along [100] the $8 \mathrm{a}_{\mathrm{c}}$ periodicity is clearly observed (area A), in accordance to the sequence ...OOOTOOOT'O... (Fig. 7b) $\left(\mathrm{O}=\right.$ octahedron, $\mathrm{T}=$ tetrahedron, $\mathrm{T}^{\prime}=$ tetrahedron with different orientation), whereas just half periodicity is measured along [001] axis. This is because along this projection the different tetrahedra orientation ( $\mathrm{T}$ and $\left.\mathrm{T}^{\prime}\right)$ cannot be distinguished (Fig. 7c).

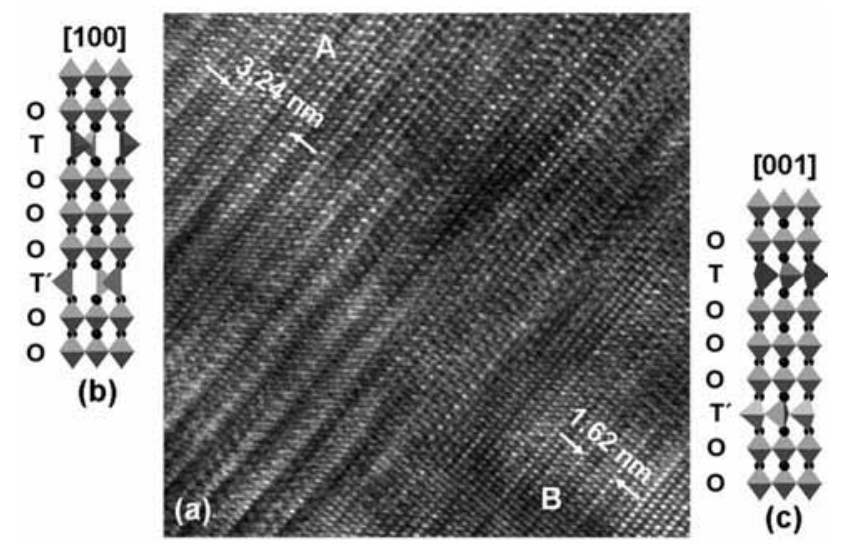

Fig. (7). (a) HREM image characteristic of $\mathrm{LaMnO}_{2.75}$ showing domains A and B, (b) Polyhedra model corresponding to A domain, (c) Polyhedra model corresponding to B domain.

The above results allow to propose a topotactic reduction pathway in $\mathrm{LaMnO}_{3}$ through the oxygen vacancy formation randomly distributed for $\delta=0.03\left(\mathrm{LaMnO}_{2.97}\right)$ giving rise to short range ordering for $\delta=0.12\left(\mathrm{LaMnO}_{2.88}\right)$ and finally to oxygen defective layers of tetrahedra that orderly intergrow with the remaining not reduced octahedral ones.

Considering the magnetic properties, $\mathrm{LaMnO}_{2.97}$ presents a magnetic behaviour similar to $\mathrm{LaMnO}_{3}$, i.e., A-type AFM ordering with $\mathrm{T}_{\mathrm{N}} \sim 130 \mathrm{~K}$. $\mathrm{LaMnO}_{2.88}$ exhibits $\mathrm{FM}$ behaviour, as observed in Fig. (8). It is worth recalling that TEM study indicates the presence of at least two phases related to the different observed crystals, i) $\mathrm{LaMnO}_{3}$ perovskite- type and ii) related to that basic structure, but exhibiting orderdisorder phenomena probably due to oxygen vacancy ordering. Since $\mathrm{LaMnO}_{3}$ is an AFM material, it seems reasonable to relate the FM behaviour to the phase exhibiting order disorder phenomena. The material shows a Curie temperature

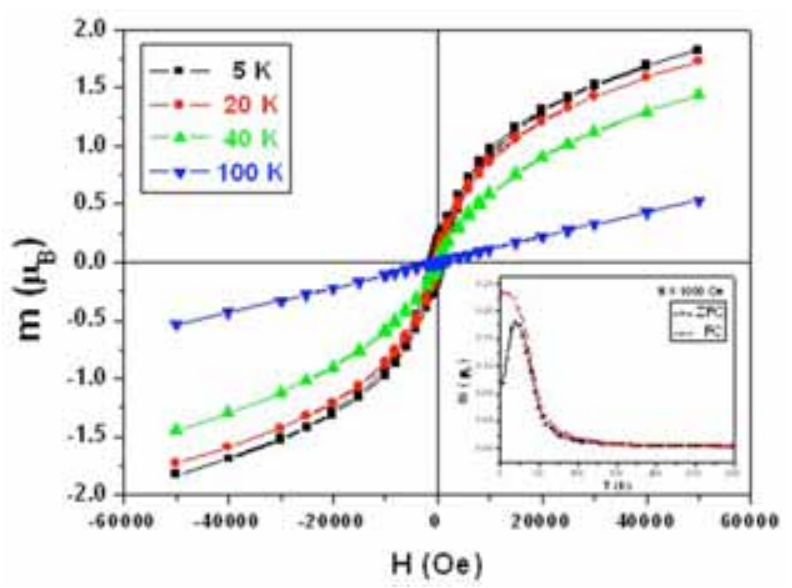

Fig. (8). Magnetization curve of $\mathrm{LaMnO}_{2.88}$ as a function of the magnetic field. The thermal dependence of the magnetization (applied field $1000 \mathrm{Oe}$ ) is shown in the inset. 
$\left(\mathrm{T}_{\mathrm{c}}\right)$ around $35 \mathrm{~K}$, as estimated from the derivative of the $\mathrm{FC}$ curve (inset Fig. 8). It is evident that the observed changes, with respect to $\mathrm{LaMnO}_{3}$, must be related not only to the $\mathrm{Mn}$ oxidation state but also to the coordination environment of the $\mathrm{Mn}^{2+}$ and $\mathrm{Mn}^{3+}$ cations, as the presence of ordered patterns of anionic vacancies.

For $\mathrm{LaMnO}_{2.75}$ a magnetic transition, at $50 \mathrm{~K}$, appears (inset $1 \mathrm{Fig}$. 9).This temperature is related to $a T_{c}$, since at higher temperatures, the material exhibits a clear paramagnetic behaviour (Fig. 9). It is worth stressing that the coercive field values increase more than 2 orders of magnitude, in the 50-2 $\mathrm{K}$ range. Actually, this fact is related to a staircase effect at low temperatures (inset 2 Fig. 9) and is due to a metamagnetic transition of non compensated A-type AFM ordering, on the octahedral layers, to FM behaviour, depending on the magnitude of the applied magnetic field.

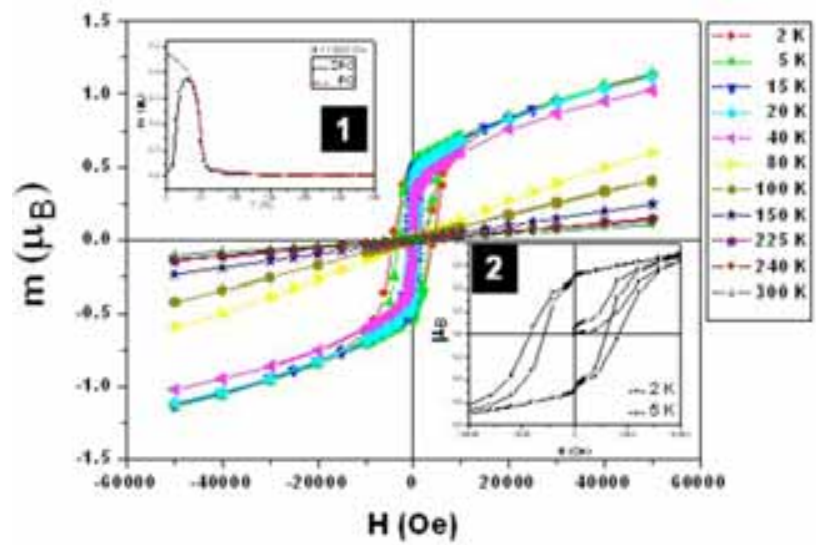

Fig. (9). Magnetization curve of $\mathrm{LaMnO}_{2.75}$ as a function of the magnetic field. The thermal dependence of the magnetization (applied field $1000 \mathrm{Oe}$ ) is shown in the inset 1. Hysteresis loops at 2 and $5 \mathrm{~K}$ are enhanced in inset 2 .

This structural-magnetic model is proposed on the basis of the topotactic reduction process which allows assuming that the magnetic order remains in the octahedral layers. For this composition, around $50 \% \mathrm{Mn}^{2+}$ and $\mathrm{Mn}^{3+}$ is expected, and again, the new and peculiar magnetic behaviour could be related to the coordination environment of the $\mathrm{Mn}^{2+}$ and $\mathrm{Mn}^{3+}$ cations as well as the presence of anionic vacancies ordering. In order to confirm the magnetic structure, neutron diffraction measurements are in progress.

\section{$\mathrm{La}_{1-\mathrm{x}} \mathrm{Sr}_{\mathrm{x}} \mathrm{MnO}_{3-\delta}$}

The reduction pathway is modified when La is partially substituted by Sr. In this case, lower oxygen content compositions $\mathrm{La}_{0.5} \mathrm{Sr}_{0.5} \mathrm{MnO}_{2.67}$ and $\mathrm{La}_{0.5} \mathrm{Sr}_{0.5} \mathrm{MnO}_{2.5}$ are stabilized, as apparently single phases. The XRD corresponding to $\mathrm{La}_{0.5} \mathrm{Sr}_{0.5} \mathrm{MnO}_{2.67}$ shows wide maxima characteristic of a cubic perovskite. The pattern for $\mathrm{La}_{0.5} \mathrm{Sr}_{0.5} \mathrm{MnO}_{2.5}$ perfectly fits with a brownmillerite cell (Ibm2), as previously reported for $\mathrm{La}_{0.5} \mathrm{Ca}_{0.5} \mathrm{MnO}_{2.5}$, of lattice parameters $\mathrm{a}=0.54117(3)$, $\mathrm{b}=1.6761(1), \mathrm{c}=0.54004(3) \mathrm{nm}$.

In order to get more reliable structural information SAED and HREM studies have been performed. In the case of $\mathrm{La}_{0.5} \mathrm{Sr}_{0.5} \mathrm{MnO}_{2.67}$, a more complex situation to that suggested by XRD has been found. Actually, two main types of crystals I and II have been found. Fig. (10a) shows a typical SAED pattern corresponding to type I which can be indexed on the basis of an orthorhombic perovskite cell $a_{c} \sqrt{ } 2,2 a_{c}$, $\mathrm{a} \sqrt{ } 2_{c}$, along [101]. The SAED pattern depicted in Fig. (10b), corresponding to type II, can be interpreted on the basis of a different orthorhombic cell of $a_{c} \sqrt{ } 2,2 \sqrt{ } 2 a_{c}, a_{c}$ parameters, along [001], characteristic of the $\mathrm{CaMnO}_{2.5}$ structural type which can be described from square-pyramids sharing corners (Fig. 1a).


Fig. (10). SAED patterns characteristic of the two type of crystal found in $\mathrm{La}_{0.5} \mathrm{Sr}_{0.5} \mathrm{MnO}_{2.67}$ (a) type one, orthorhombic perovskite and (b) type two, $\mathrm{Ca}_{2} \mathrm{Mn}_{2} \mathrm{O}_{5}$-type.

A representative HREM image of type I along [101] zone axis is depicted in Fig. (11a) where two domains are evident. Each domain A and $\mathrm{B}$ exhibits periodicities of $0.80 \times 0.39$ and $0.39 \times 0.39$, respectively, characteristic of the orthorhombic perovskite cell along [101] and [001] zone axes, respectively, as confirmed by the corresponding Fourier Transform (FT) (Fig. 11b-c).

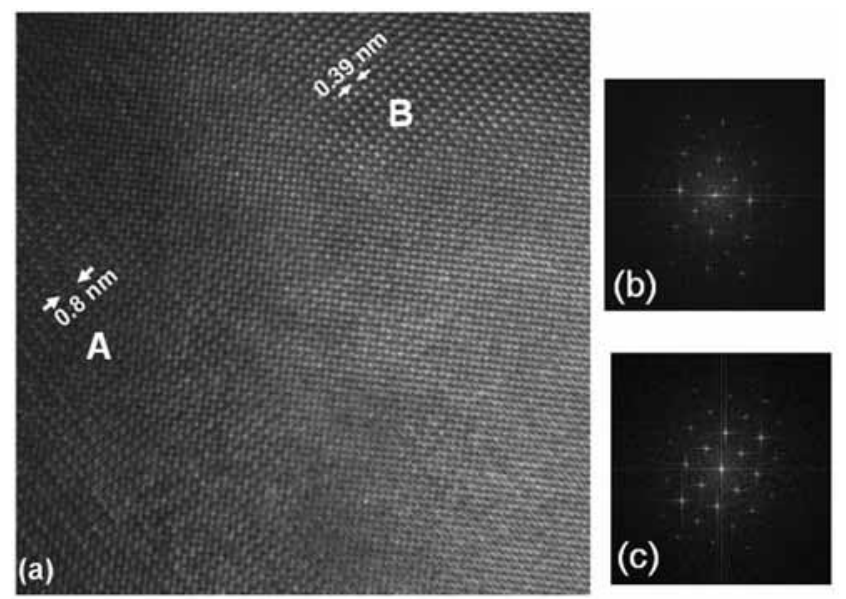

Fig. (11). (a) HREM image characteristic of type I crystal of $\mathrm{La}_{0.5} \mathrm{Sr}_{0.5} \mathrm{MnO}_{2.67}$, (b) FT transform of domain A, (c) FT of domain B.

Fig. (12a) shows an image along [001] zone axis characteristic of the type II in which the observed periodicities as well as the FT (Fig. 12b) confirm the $\mathrm{CaMnO}_{2.5}$ type cell along this projection (Fig. 12c). For $\mathrm{La}_{0.5} \mathrm{Sr}_{0.5} \mathrm{MnO}_{2.5}$ the SAED and HREM studies confirm the brownmillerite cell [26]. It is, again, remarkable the presence of twinned domains in each crystal as reflected in the HREM image displayed in Fig. (13a). Domains A and B corresponding to the $\left[10^{1}\right]_{\mathrm{B}}$ and $[010]_{\mathrm{B}}$ zone axes are evident, as confirmed by the corresponding FT for each domain (Fig. 13b-c).

The above results are quite surprising because the reduction process leads to the stabilization of a brownmillerite phase for $\mathrm{La}_{0.5} \mathrm{Sr}_{0.5} \mathrm{MnO}_{2.5}$ through an unexpected mechanism. Actually, in this phase the oxygen vacancies are ac- 
commodated in alternate layers along [101] due to the tetrahedra formation, as a consequence of ordered arrangement of the anionic vacancies (Fig. 2c). However, for the $\mathrm{La}_{0,5} \mathrm{Sr}_{0.5} \mathrm{MnO}_{2.67}$ composition, which fits with the one expected for a $\mathrm{n}=3$ term of the $\mathrm{A}_{\mathrm{n}} \mathrm{B}_{\mathrm{n}} \mathrm{O}_{3 \mathrm{n}-1}$ homologous series, a different oxygen vacancy arrangement is observed. First of all, a single phase has not been stabilized but two phases corresponding to higher and lower oxygen stoichiometry, respectively. The lower oxygen stoichiometry phase is isostructural to $\mathrm{CaMnO}_{2.5}$. The vacancy pattern in this phase is along [101] direction since only one of each two oxygen position is eliminated (Fig. $\mathbf{2 b}$ ).

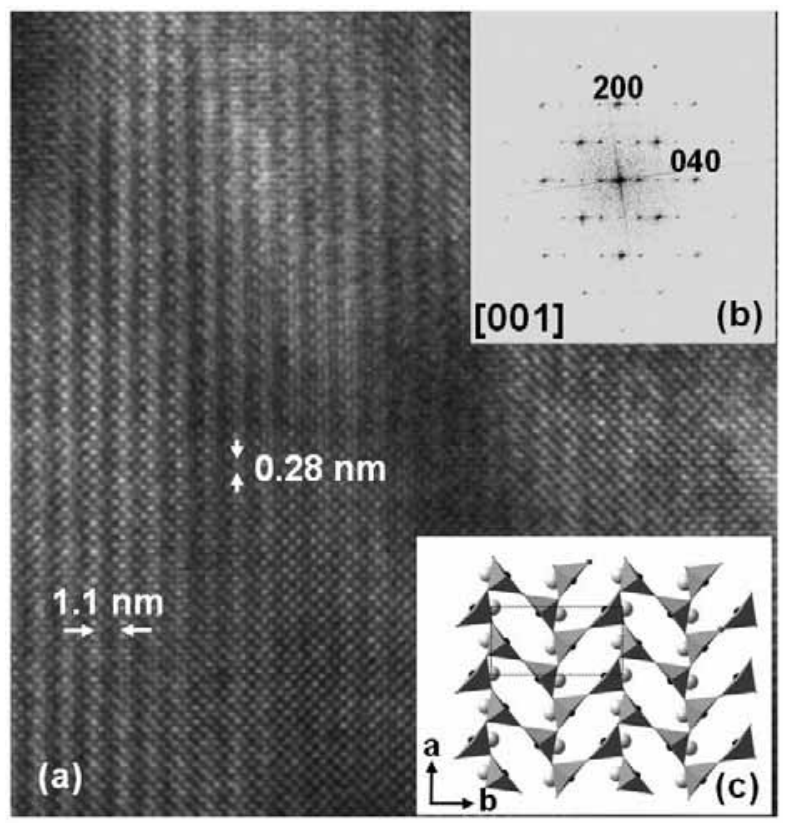

Fig. (12). (a) HREM image characteristic of type II crystal of $\mathrm{La}_{0.5} \mathrm{Sr}_{0.5} \mathrm{MnO}_{2.67}$, (b) corresponding FT, (c) polyhedra model.

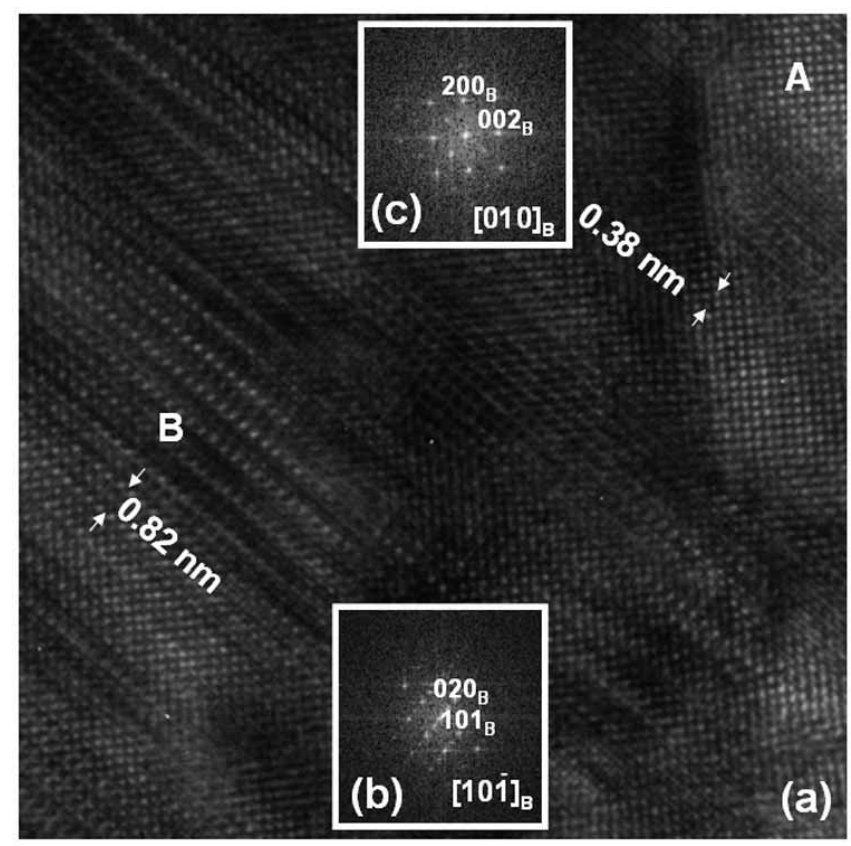

Fig. (13). (a) HREM image characteristic of $\mathrm{La}_{0.5} \mathrm{Sr}_{0.5} \mathrm{MnO}_{2.5}$, (b) FT transform of domain A, (c) FT of domain B.
Taking into account these facts it seems that the reduction process starts with the square-pyramids formation but develops in the tetrahedra when the oxygen content is further decreased.

From the point of view of the magnetic behaviour, $\mathrm{La}_{0.5} \mathrm{Sr}_{0.5} \mathrm{MnO}_{2.67}$ exhibits FM and AFM contributions (Fig. 14a). In this case, the FM behaviour can be related to the presence of the starting FM perovskite $\mathrm{La}_{0.5} \mathrm{Sr}_{0.5} \mathrm{MnO}_{3}$. For this reason, it seems reasonable to assign the second contribution, i.e., AFM behaviour to the $\mathrm{Ca}_{2} \mathrm{Mn}_{2} \mathrm{O}_{5}$ type-crystals. For $\mathrm{La}_{0.5} \mathrm{Sr}_{0.5} \mathrm{MnO}_{2.5}$, neutron diffraction experiments indicate an AFM behaviour, in accordance with the G-type AFM ordering exhibited by related brownmillerite compounds [33]. In addition, SQUID measurements reveal a FM contribution (Fig. 14b). In this case, this FM contribution cannot be related to the starting material. According to previous XANES data [19], the coexistence of $\mathrm{Mn}^{2+}, \mathrm{Mn}^{3+}$ and $\mathrm{Mn}^{4+}$ would be expected in $\mathrm{La}_{0.5} \mathrm{Sr}_{0.5} \mathrm{MnO}_{2.5}$, isostructural to $\mathrm{La}_{0.5} \mathrm{Ca}_{0.5} \mathrm{MnO}_{2.5}$. Based on these results, a model in which $\mathrm{Mn}^{2+}$ is located at the tetrahedral layers while $\mathrm{Mn}^{3+}$ and $\mathrm{Mn}^{4+}$ and the rest of $\mathrm{Mn}^{2+}$ occupies the octahedral ones is proposed [26]. However, the presence of $\mathrm{Mn}^{3+}$ and $\mathrm{Mn}^{4+}$ at the octahedral position is not enough to ensure the FM behaviour because it appears in $\mathrm{La}_{0.5} \mathrm{Sr}_{0.5} \mathrm{MnO}_{2.5}$ but not in $\mathrm{La}_{0.5} \mathrm{Ca}_{0.5} \mathrm{MnO}_{2.5}$. Although, both compounds exhibit brownmillerite structure, they differ on the structural distortion. The Sr-brownmillerite is less distorted involving Mn octahedral angles close to $180^{\circ}$. This condition is required for the existence of double exchange interactions, and for this reason, this material exhibits FM interactions [26]. Besides, this model allows proposing a bidimensional FM character because this magnetic contribution is confined in the octahedral layers.
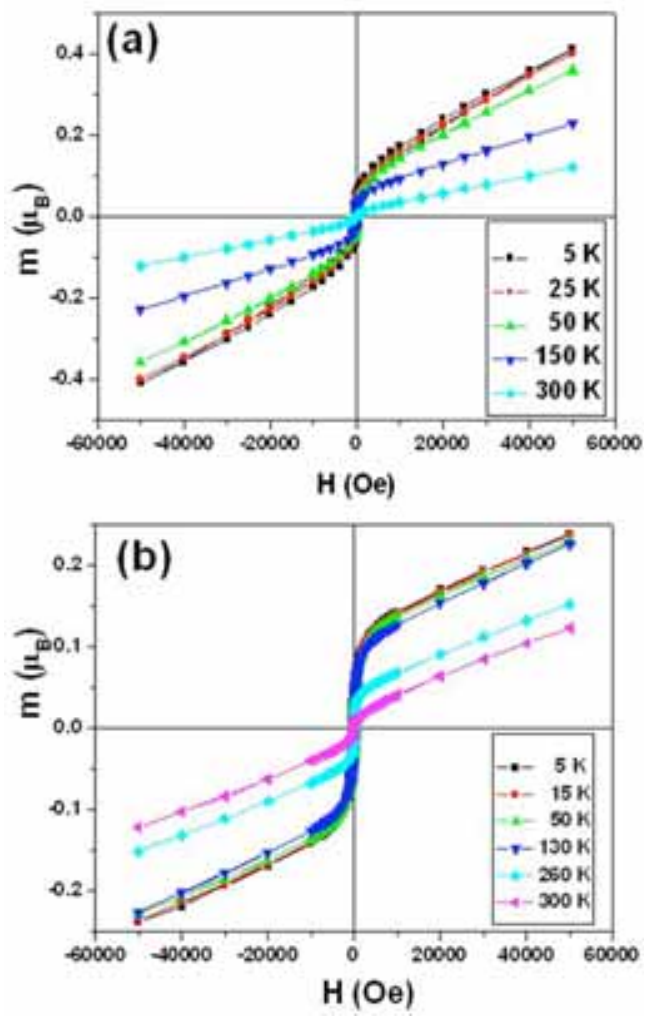

Fig. (14). Magnetization curves of (a) $\mathrm{La}_{0.5} \mathrm{Sr}_{0.5} \mathrm{MnO}_{2.67}$ and (b) $\mathrm{La}_{0.5} \mathrm{Sr}_{0.5} \mathrm{MnO}_{2.5}$ as a function of the magnetic field. 
The crystallographic structure and octahedral $\left[\mathrm{MnO}_{6}\right]$ distortion are essential in the magnetic properties of manganites [34], exhibiting perovskite structure, being governed by the tolerance factor, $t$. In this sense, for fixed oxygen content this value depends on the ionic radius of cations at the $\mathrm{A}$ and B perovskite positions. In this sense, small variations in the size of these cations will produce important differences in the magnetic and electric properties. The $\mathrm{La}_{0.5} \mathrm{Sr}_{0.5} \mathrm{MnO}_{3}$, $\mathrm{La}_{0.5} \mathrm{Ca}_{0.5} \mathrm{MnO}_{3}$ and $\mathrm{Nd}_{0.5} \mathrm{Sr}_{0.5} \mathrm{MnO}_{3}$ perovskites corroborate this fact. Actually, all of them exhibit $50 \%$ of $\mathrm{Mn}^{3+}$ and 50 $\%$ of $\mathrm{Mn}^{4+}$. However, $\mathrm{La}_{0.5} \mathrm{Ca}_{0.5} \mathrm{MnO}_{3}$ and $\mathrm{Nd}_{0.5} \mathrm{Sr}_{0.5} \mathrm{MnO}_{3}$ exhibit AFM with charge ordering at 190 and $150 \mathrm{~K}$, respectively while $\mathrm{La}_{0.5} \mathrm{Sr}_{0.5} \mathrm{MnO}_{3}$ presents $\mathrm{FM}$ behaviour. This fact is in agreement with the structural differences reflected in similar $\mathrm{t}$ factors for $\mathrm{La}_{0.5} \mathrm{Ca}_{0.5} \mathrm{MnO}_{3}$ and $\mathrm{Nd}_{0.5} \mathrm{Sr}_{0.5} \mathrm{MnO}_{3}$ but different to the one corresponding to $\mathrm{La}_{0.5} \mathrm{Sr}_{0.5} \mathrm{MnO}_{3}$ [34], which involves less orthorhombic distortion as a consequence of the bigger $\mathrm{Sr}$ size. Moreover, this involves $\mathrm{Mn}-\mathrm{O}-$ Mn angles around $180^{\circ}$, which favours FM interactions by double exchange mechanism. In a similar way, it seems interesting to evaluate the influence of the alkaline-earth and the lanthanide cations in the reduced samples. In order to do that, the $\mathrm{O}_{2.5}$ stoichiometry was chosen because of the stabilization of brownmillerite single phases for $\mathrm{La}_{0.5} \mathrm{Ca}_{0.5} \mathrm{MnO}_{2.5}$, $\mathrm{La}_{0.5} \mathrm{Sr}_{0.5} \mathrm{MnO}_{2.5}$ and $\mathrm{Nd}_{0.5} \mathrm{Sr}_{0.5} \mathrm{MnO}_{2.5}$. XRD and SAED patterns can be indexed in all the cases on the basis of a brownmillerite (Ibm2) unit cell (parameters are gathered in Table 2).

Table 2. Lattice Parameters of $\mathrm{Ln}_{1-\mathrm{x}} \mathrm{AT}_{\mathrm{X}} \mathrm{MnO}_{2.5}$

\begin{tabular}{|c|c|c|c|}
\hline $\mathbf{L a} \mathbf{a}_{\mathbf{1 - x}} \mathbf{A} \mathbf{T}_{\mathbf{0 . 5}} \mathbf{M n O}_{2.5}$ & $\mathbf{a}(\mathbf{n m})$ & $\mathbf{b}(\mathbf{n m})$ & $\mathbf{c}(\mathbf{n m})$ \\
\hline \hline $\mathrm{La}_{0.5} \mathrm{Sr}_{0.5} \mathrm{MnO}_{2.5}$ & $0.541(3)$ & $1.676(1)$ & $0.540(3)$ \\
\hline $\mathrm{La}_{0.5} \mathrm{Ca}_{0.5} \mathrm{MnO}_{2.5}$ & $0.536(3)$ & $1.644(9)$ & $0.534(3)$ \\
\hline $\mathrm{La}_{0.67} \mathrm{Ca}_{0.33} \mathrm{MnO}_{2.5}$ & $0.523(3)$ & $1.666(3)$ & $0.522(3)$ \\
\hline $\mathrm{La}_{0.33} \mathrm{Ca}_{0.67} \mathrm{MnO}_{2.5}$ & $0.556(6)$ & $1.618(6)$ & $0.542(6)$ \\
\hline $\mathrm{Nd}_{0.5} \mathrm{Sr}_{0.5} \mathrm{MnO}_{2.5}$ & $0.538(4)$ & $1.660(4)$ & $0.537(4)$ \\
\hline
\end{tabular}

The magnetic measurements reveal similar behaviour to that observed in the starting perovskites. $\mathrm{La}_{0.5} \mathrm{Sr}_{0.5} \mathrm{MnO}_{2.5}$, as mentioned before, exhibits FM while AFM ordering, with a $\mathrm{T}_{\mathrm{N}}$ around $130 \mathrm{~K}$, is found for both $\mathrm{La}_{0.5} \mathrm{Ca}_{0.5} \mathrm{MnO}_{2.5}$ and $\mathrm{Nd}_{0.5} \mathrm{Sr}_{0.5} \mathrm{MnO}_{2.5}$ samples. It is worth recalling, the high magnetization values for neodymium brownmillerite in spite of the AFM behaviour, probably influenced by the magnetic character of Nd. Actually, the magnetic moment, at $5 \mathrm{~K}$ and $5 \mathrm{~T}$ (Fig. 15), is higher for this composition than $\mathrm{La}_{0.5} \mathrm{Sr}_{0.5} \mathrm{MnO}_{2.5}$, in spite of this material exhibits a noticeable FM contribution. The orthorhombic distortion of the perovskite starting materials remains in the corresponding brownmillerites (Table 2). It means that, again, the $\mathrm{LaSr}$ is less distorted than the $\mathrm{LaCa}$ and $\mathrm{NdSr}$ ones and then the FM and AFM behaviours, respectively, are maintained.

The above tendency is also observed when the $\mathrm{La} / \mathrm{Ca}$ ratio is changed. In this case, $\mathrm{La}_{0.67} \mathrm{Ca}_{0.33} \mathrm{MnO}_{2.5}$ and $\mathrm{La}_{0.33} \mathrm{Ca}_{0.67} \mathrm{MnO}_{2.5}$ compositions show, again, in agreement with XRD (Table 2) and SAED studies, brownmillerite structure.
For $\mathrm{La}_{0.67} \mathrm{Ca}_{0.33} \mathrm{MnO}_{2.5}$, the magnetic behaviour, in accordance with the structural distortion in the corresponding perovskite, is a FM, with $\mathrm{T}_{\mathrm{c}}$ around $250 \mathrm{~K}$, while it is AFM for $\mathrm{La}_{0.33} \mathrm{Ca}_{0.67} \mathrm{MnO}_{2.5}$ (Fig. 16).



Fig. (15). Magnetization curve of $\mathrm{Ln}_{0.5} \mathrm{AT}_{0.5} \mathrm{MnO}_{2.5}$ as a function of the magnetic field.
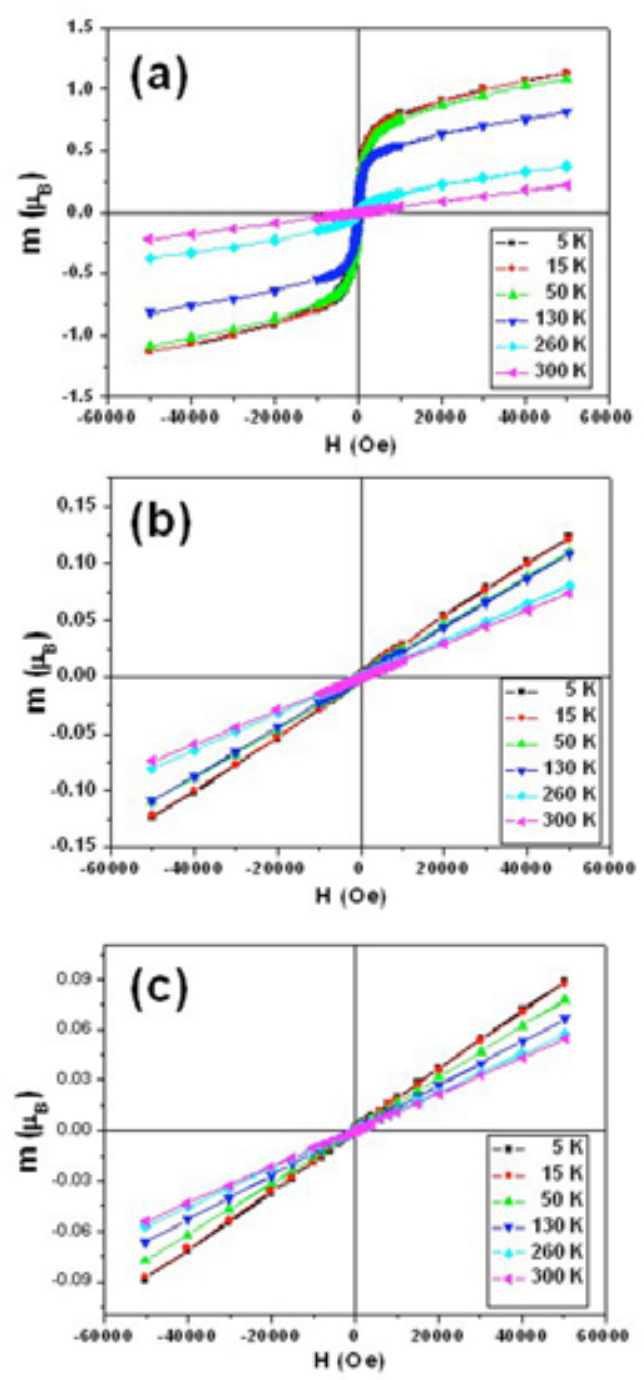

Fig. (16). Magnetization curves as a function of the magnetic field, (a) $\mathrm{La}_{0.67} \mathrm{Ca}_{0.33} \mathrm{MnO}_{2.5}$; (b) $\mathrm{La}_{0.5} \mathrm{Ca}_{0.5} \mathrm{MnO}_{2.5}$; (c) $\mathrm{La}_{0.33} \mathrm{Ca}_{0.67} \mathrm{MnO}_{2.5}$. 


\section{CONCLUSIONS}

The ensemble of these results allow proposing the stabilization of several $\mathrm{La}_{1-\mathrm{x}} \mathrm{AT}_{\mathrm{x}} \mathrm{MnO}_{3-\delta}$ phases, with slightly different compositions, related to the perovskite, brownmillerite and $\mathrm{Ca}_{2} \mathrm{Mn}_{2} \mathrm{O}_{5}$ structural types by means of a reduction process. For $\mathrm{x}=0$, the experimental data suggest a topotactic reduction mechanism through tetrahedral layers formation. However, a more complex reduction process has been found for $\mathrm{x}=0.5$ in $\mathrm{La}_{0.5} \mathrm{Sr}_{0.5} \mathrm{MnO}_{2.5}$ and $\mathrm{La}_{0.5} \mathrm{Ca}_{0.5} \mathrm{MnO}_{2.5}$ due to the formation of intermediate phases related to $\mathrm{Ca}_{2} \mathrm{Mn}_{2} \mathrm{O}_{5}$, involving square-pyramids. Besides, this structural complexity linked to three and two $\mathrm{Mn}$ oxidation states for the $\mathrm{x}=0.5$ $\left(\mathrm{Mn}^{2+}, \mathrm{Mn}^{3+}\right.$ and $\left.\mathrm{Mn}^{4+}\right)$ and $\mathrm{x}=0\left(\mathrm{Mn}^{2+}\right.$ and $\left.\mathrm{Mn}^{3+}\right)$ samples, respectively, is responsible for the several magnetic behaviours observed. On the other hand, and generally speaking, the FM fraction in oxygen deficient manganites decreases for high concentration of vacancies, since anionic vacancy introduction breaks the $\mathrm{Mn}^{4+}-\mathrm{O}-\mathrm{Mn}^{3+}$ double exchange interactions avoiding the FM ordering. On the basis of this description two situations can be attained (i) when vacancies are randomly distributed the magnetic behaviour of the starting material is lost while (ii) it is partially kept when ordering between octahedral and tetrahedral layers happens. This is possible because the FM interactions remain at the octahedral layers. It is then clear that, together with the more conventional synthetic strategies, chemical doping and more recently cationic vacancy formation, the anion vacancies can also play an important role in the intriguing structureproperties relationships in manganites. Moreover, synthesis under controlled atmosphere provides an additional chemical strategy which is the possibility to study the reductionoxidation process simultaneously, i.e., its reversibility. In this sense, it is worth remembering that the red-ox reaction $\mathrm{La}_{0.5} \mathrm{Ca}_{0.5} \mathrm{MnO}_{3} \rightarrow \mathrm{La}_{0.5} \mathrm{Ca}_{0.5} \mathrm{MnO}_{2.5}$ undergoes different pathways, involving different $\mathrm{Mn}$ oxidation states as well as microstructural features at each state, as confirmed by XANES and TEM, respectively. Actually, $\mathrm{Mn}^{3+}$ and $\mathrm{Mn}^{4+}$ are present in the $\mathrm{O}_{3} \rightarrow \mathrm{O}_{2.5}$ reduction process while $\mathrm{Mn}^{2+}$, $\mathrm{Mn}^{3+}$ and $\mathrm{Mn}^{4+}$ coexist in the oxidation $\mathrm{O}_{2.5} \rightarrow \mathrm{O}_{3}$ one [19]. From the structural point of view, the reduction comprises the presence of octahedra and square-pyramids unities while disorder sequence characteristic of brownmillerite and perovskites are present in the oxidation. This fact indicates that it is possible to stabilize samples with the same anionic and cationic composition but with differences in the Mn oxidation states. This situation, again, enhances the alternatives to deal with new magnetic behaviours and the possibility to design materials containing the adequate building blocks and oxidation states required for a given property. On the other hand, it is evident that the reduction mechanism was different in the $\mathrm{LaMnO}_{3}$ and $\mathrm{LaMnO}_{3}$ alkaline-earth doped systems. In a similar way, it has been reported that the introduction of cationic vacancies leads to different results in $\mathrm{Ca}$ doped or free $\mathrm{La}_{1-\mathrm{t}} \mathrm{Mn}_{1-\mathrm{t}} \mathrm{O}_{3}$ systems. In this case, the introduction of calcium acts not only as $\mathrm{Mn}^{4+}$ supplier but also influence on the magnetic and electric behaviour of the La-Ca$\mathrm{Mn}-\mathrm{O}$. This role of $\mathrm{Ca}$ contrasts with the extended idea that the manganese is the only important ion in terms of magnetic and electric behaviour [35]. In this sense, the electric and magnetic phase diagram should have an additional dimension taking into account either the $\mathrm{Ca}^{2+}$ or $\mathrm{Mn}^{4+}$ concentration [15].

\section{REFERENCES}

[1] von Helmolt, R.; Wecker, J.; Holzapfel, B.; Schultz, L.; Samwer, K. Phys. Rev. Lett., 1993, 14, 2331.

[2] Chahara, K.; Ohno, T.; Kasai, M.; Kozona, Y. Appl. Phys. Lett., 1993, 63, 1990.

[3] Schiffer, P.; Ramirez, A. P.; Bao, W.; Cheong, S.-W. Phys. Rev. Lett., 1995, 75, 3348.

[4] Cheong, C.-W.; Hwang, H.Y. Ferromagnetism vs Charge/Orbital Ordering in Mixed-Valent Manganites, in Colossal Magnetoresistance Oxides, Tokura. Y.; Gordon \& Breach Science Publishers, Advances in Condensed Matter Science, Singapore, 2000; vol. 2.

[5] Tofield, B. C.; Scott, W. R. J. Solid State Chem., 1975, 10, 183.

[6] Van Roosmalen, J. A. M.; Cordfunke, E. H. P.; Helmholdt, R. B.; Zandbergen, H. W. J. Solid State Chem., 1994, 110, 106; 110, 109; $110,113$.

[7] Zener, C. Phys. Rev., 1951, 81, 440; 82, 403.

[8] Verelst, M.; Rangavittal, N.; Rao, C. N. R.; Rousset, A. J. Solid State Chem., 1993, 104, 74.

[9] Huang, Q.; Santoro, A.; Lynn, J. W.; Erwin, R. W.; Borches, J. A.; Peng, J. L.; Greene, R. L. Phys. Rev. B, 1997, 55, 14987.

[10] Topfer, J.; Goodenough, J. B. J. Solid State Chem., 1997, 130, 11.

[11] Prado, F.; Sánchez, R. D.; Caneiro, A.; Causa, M. T.; Tovar, M. J. Solid State Chem., 1999, 146, 418.

[12] Alonso, J.; Herrero, E.; Gonzalez-Calbet, J. M.; Vallet-Regí, M.; Martínez, J. L.; Rojo, J. M.; Hernando, A. Phys. Rev. B, 2000, 62, 11328.

[13] Herrero, E.; Alonso, J.; Martínez, J. L.; Vallet-Regí, M.; GonzalezCalbet, J. M. Chem. Mater., 2000, 12, 1060.

[14] Alonso, J.; Arroyo, A.; Gonzalez-Calbet, J. M.; Vallet-Regí, M.; Martínez, J. L.; Rojo, J. M.; Hernando, A. Phys. Rev. B, 2001, 64, 172410.

[15] Alonso, J. M.; Arroyo, A.; Gonzalez-Calbet, J. M.; Hernando, A.; Rojo, J. M.; Vallet-Regí, M. Chem. Mater., 2003, 15, 2864.

[16] Gong, G. Q.; Canedy, C.; Xiao, G.; Sun, J. Z.; Gupta, A.; Gallagher, W. J. Appl. Phys. Lett., 1995, 67, 1783.

[17] Radaelli, P. G.; Cox, D.E.; Marezio, M.; Cheong, S-W.; Schiffer, P.E., Ramirez, A. P. Phys. Rev. Lett., 1995, 75, 4488.

[18] Chen, C. H.; Cheong, S-W. Phys Rev. Lett., 1996, 76, 4042.

[19] Alonso, J. M.; Cortés-Gil, R.; Ruiz-González, L.; González-Calbet, J. M.; Hernando, A.; Vallet-Regí, M.; Dávila, M. E.; Asensio, M. C. Eur. J. Inorg. Chem., 2007, 21, 3350.

[20] Reller, A.; Thomas, J. M.; Jefferson, F. R. S. D. A.; Uppal, M. K. Proc. R. Soc. Lond. A, 1984, 394, 223.

[21] Reller, A.; Davoodabady, G.; Oswald, H. R Thermochim. Acta, 1985, 83, 121.

[22] Kamata, K.; Nakajima, T.; Hayashi, T.; Nakamura, T. Mater. Res. Bull., 1978, 13, 49.

[23] González-Calbet, J. M.; Herrero, E.; Rangavittal, N.; Alonso, J. M.; Martínez, J. L.; Vallet-Regí, M. J. Solid State Chem., 1999, 148, 158.

[24] Hansteen, O.; Bréard, Y.; Fjellvag, H.; Hauback, B. Solid State Sci., 2004, 6, 279.

[25] Ruiz-González, M. L.; Cortés-Gil, R.; Alonso, J. M.; Hernando, A.; Vallet-Regí, M.; González-Calbet, J. M. Chem. Mater., 2006, 18, 5756.

[26] Cortés-Gil, R.; Ruiz-González, M. L.; Alonso, J. M.; Vallet-Regí, M.; Hernando, A.; González-Calbet, J. M. Chem. A Eur. J., 2007, $13,4246$.

[27] González-Calbet, J. M.; Vallet-Regí, M. J. Solid State Chem., 1987, $68,266$.

[28] Hovmöller, S.; Xiaodong, Z; Neng Wang, D.; Gonzalez-Calbet, J. M.; Vallet-Regi, M. J. Solid State Chem., 1988, 77, 316.

[29] Grenier, J. C.; Darriet, J.; Pouchard, M.; Hagenmuller, P. Mater. Res. Bull., 1976, 11, 1219.

[30] Alario-Franco, M. A.; Henche, M. J.; Vallet-Regí, M.; GonzálezCalbet, J. M.; Grenier, J. C.; Wattiaux, A.; Hagenmuller, P. J. Solid State Chem., 1983, 46, 23. 
[31] Komornicki, S.; Grenier, J. C.; Pouchard, M.; Hagenmuller, P. P. Nuovo J. Chim., 1981, 5, 161.

[32] Vegas, A.; Vallet-Regí, M.; Gonzalez-Calbet, J. M.; Alario-Franco, M. Acta Cryst., 1986, B42,167.

[33] Abakumov, A. M.; Rozova, M. G.; Antipov, E. V. Russian Chem. Rev., 2004, 73, 847 .
[34] Tokura, Y. Fundamental Features of Colossal Magnetoresistive Manganese Oxides, Gordon \& Breach Science Publishers, Advances in Condensed Matter Science, Singapore, 2000; vol. 2.

[35] Millis, A. J. Theory of CMR Manganites, in Colossal Magnetoresistance Oxides, Tokura. Y.; Gordon \& Breach Science Publishers, Advances in Condensed Matter Science, Singapore, 2000; vol. 2. 